\title{
Inability of Diapausing Culex pipiens (Diptera: Culicidae) to Use Blood for Producing Lipid Reserves for Overwinter Survival
}

\author{
Mitchell, Carl J ; Briegel, Hans
}

\begin{abstract}
Diapausing Culex pipiens L. females fed $10 \%$ sucrose for $7 \mathrm{~d}$ following eclosion contained significantly more lipids $(\mathrm{P}<0.05)$ than nondiapausing females reared and maintained at the same temperature $\left(22^{\circ} \mathrm{C}\right)$ but at a longer photophase (14:10 [L:D] instead of 9:15). Diapausing females with limited lipid reserves failed to increase their reserves after blood feeding. The average lipid content of 56 females tested decreased significantly $(\mathrm{P}<0.05)$ by day 6 after feeding and there was no correlation $(\mathrm{r}=-0.06)$ between lipid content at this time and original bloodmeal volumes of individual females. These results refute the contention that blood meals taken by diapausing $\mathrm{Cx}$. pipiens result in fat body development when females are incubated at $18^{\circ} \mathrm{C}$ during bloodmeal digestion. Diapausing Cx. pipiens with limited lipid reserves were unable to obtain sufficient energy from a single blood meal to survive extended hibernation. Although none became gravid, only $50 \%$ remained alive after $20 \mathrm{~d}$ in hibernation. In contrast, nonblood-fed females fed only $10 \%$ sucrose for 7 to $10 \mathrm{~d}$ before being placed in hibernation on a water diet survived for 6 mo with only $50 \%$ mortality. There was no evidence for gonotrophic dissociation. Failure of blood-fed, diapausing females to initiate vitellogenesis was correlated with the significantly smaller blood meals taken by most diapausing females and not with hypertrophy of the fat body or temperature during digestion
\end{abstract}

DOI: https://doi.org/10.1093/jmedent/26.4.318

Posted at the Zurich Open Repository and Archive, University of Zurich

ZORA URL: https://doi.org/10.5167/uzh-155154

Journal Article

Published Version

Originally published at:

Mitchell, Carl J; Briegel, Hans (1989). Inability of Diapausing Culex pipiens (Diptera: Culicidae) to Use Blood for Producing Lipid Reserves for Overwinter Survival. Journal of Medical Entomology, 26(4):318326.

DOI: https://doi.org/10.1093/jmedent/26.4.318 


\title{
Inability of Diapausing Culex pipiens (Diptera: Culicidae) to Use Blood for Producing Lipid Reserves for Overwinter Survival
}

\author{
CARL J. MITCHELL' AND HANS BRIEGEL ${ }^{2}$
}

\begin{abstract}
J. Med. Entomol. 26(4): 318-326 (1989)
ABSTRACT Diapausing Culex pipiens $\mathrm{L}$. females fed $10 \%$ sucrose for $7 \mathrm{~d}$ following eclosion contained significantly more lipids $(P<0.05)$ than nondiapausing females reared and maintained at the same temperature $\left(22^{\circ} \mathrm{C}\right)$ but at a longer photophase $(14: 10$ [L:D] instead of 9:15). Diapausing females with limited lipid reserves failed to increase their reserves after blood feeding. The average lipid content of 56 females tested decreased significantly $(P<$ $0.05)$ by day 6 after feeding and there was no correlation $(r=-0.06)$ between lipid content at this time and original bloodmeal volumes of individual females. These results refute the contention that blood meals taken by diapausing $C x$. pipiens result in fat body development when females are incubated at $18^{\circ} \mathrm{C}$ during bloodmeal digestion. Diapausing $C x$. pipiens with limited lipid reserves were unable to obtain sufficient energy from a single blood meal to survive extended hibernation. Although none became gravid, only $50 \%$ remained alive after $20 \mathrm{~d}$ in hibernation. In contrast, nonblood-fed females fed only $10 \%$ sucrose for 7 to $10 \mathrm{~d}$ before being placed in hibernation on a water diet survived for 6 mo with only $50 \%$ mortality. There was no evidence for gonotrophic dissociation. Failure of blood-fed, diapausing females to initiate vitellogenesis was correlated with the significantly smaller blood meals taken by most diapausing females and not with hypertrophy of the fat body or temperature during digestion.
\end{abstract}

KEY WORDS Insecta, diapause, Culex pipiens, overwintering

IN COOL, TEMPERATE AREAS, Culex pipiens L. survives the winter as nulliparous, inseminated females that enter facultative reproductive diapause. The larval and pupal stages are responsive to environmental cues, decreasing photophases and cool temperatures, and the program for diapause has been set for the female by the time of eclosion (Sanburg \& Larsen 1973). The male does not enter diapause and does not survive the winter. The diapausing female is further characterized by an absence of host-seeking behavior (Mitchell 1983, Bowen et al. 1988) and by hypertrophy of the fat body that serves as an energy reservoir (Buxton 1935). The female builds fat reserves before entering hibernation principally, if not exclusively, from plant juices that are rich in carbohydrates.

Although diapausing $C x$. pipiens do not display host-seeking behavior (Mitchell 1983, Bowen et al. 1988), a characteristic that should effectively preclude blood feeding in nature, some females can be induced to take a blood meal if the host-seeking step is bypassed, and they are placed in contact with or in proximity to a host for a prolonged period (Mitchell 1983). It has been reported that diapausing Cx. pipiens induced to take a blood meal

\footnotetext{
' Division of Vector-Borne Viral Diseases, Center for Infectious Diseases, Centers for Disease Control, Public Health Service, U.S Department of Health and Human Services, P.O. Box 2087, Fort Collins, Colo. 80522.

2 Department of Zoology, University of Zurich, CH-8057 Zurich, Switzerland.
}

use the blood for fat body development and not for ovarian development (Eldridge \& Bailey 1979, Eldridge 1981). However, the data upon which these reports are based (Eldridge 1968) do not support this conclusion, because the blood-fed females were given $5 \%$ sucrose for $7 \mathrm{~d}$ before bloodfeeding and continuously thereafter for an unspecified period before being tested for fat content. Therefore, it is impossible to determine whether the blood meal resulted in supplemental fat deposits in excess of those built from the $5 \%$ sucrose. Bloodmeal volumes were not determined, and a mosquito was considered to have fed if even a trace of blood was visible within the abdomen (Eldridge 1968). Further, the fat content of females fed on blood and $5 \%$ sucrose did not differ significantly after digestion of the blood from that of females fed only $5 \%$ sucrose.

Sugar is a suitable substrate for making fat (Van Handel 1965), and there is no ecological basis for assuming that fat females would seek a blood meal for making more fat or for immediate energy needs. Conceivably, however, situations might occasionally arise where recently emerged diapausing females have difficulty in obtaining sufficient carbohydrates for building fat reserves. It is these individuals that would be expected to show the largest increase in fat reserves following digestion of a blood meal if, indeed, blood is used for this purpose by diapausing females. We have investigated this question and also whether diapausing females can obtain sufficient energy from a single 
blood meal for overwinter survival. Ancillary data were obtained on whether fat body size in diapausing females influences the initiation of vitellogenesis or the volume of blood retained at the end of overnight feeding periods.

\section{Materials and Methods}

A strain of Cx. pipiens from Ft. Collins, Colo., colonized since 1981 and known to enter diapause uniformly when exposed to short day lengths and cool temperatures (Wilton \& Smith 1985, Bowen et al. 1988) was used. The colony was maintained at $27^{\circ} \mathrm{C}, 85 \% \mathrm{RH}$, and a photoperiod of $14: 10$ (L:D). Larvae were reared on a high protein diet (Lea 1964). Adults were maintained on $10 \%$ sucrose and allowed to feed overnight once each week on a chicken.

Diapausing females were reared from the egg or first instar at $22^{\circ} \mathrm{C}$ and 9:15 (L:D). Larvae were fed the same diet as the stock colony; however, the feeding period was extended from 8 to $11 \mathrm{~d}$ because of slowed development at the cooler temperature. Some nondiapausing adults also were reared at $22^{\circ} \mathrm{C}$ and 14:10 (L:D) and fed for the same extended period for comparative purposes. Adults were given 1 or $10 \%$ sucrose ad lib. from the time of eclosion until they were offered a blood meal or tested for energy reserves. Some adults were tested for reserves at the time of adult eclosion without being fed. Ovarian follicles were dissected in saline, and their lengths were measured along with those of attached germaria at $100 \times$ under a compound microscope. A follicle/germarium ( $F: G$ ) ratio equal to or less than $1.5: 1$ was used as the criterion for ovarian diapause (Spielman \& Wong 1973). Diapausing females were induced to feed on blood by placing groups of $50 \mathrm{in} 250-\mathrm{ml}\left(0.00025 \mathrm{~m}^{3}\right)$ plastic cups covered with netting upon which a small chick was restrained overnight (1630 to 0800 hours) at $22^{\circ} \mathrm{C}$, 9:15 (L:D), with lights off at 1700 hours. Colony females and females in which diapause had been broken by exposure to $14: 10$ (L:D) and $27^{\circ} \mathrm{C}$ for $1 \mathrm{wk}$ were fed in the same manner. The age of the females varied and is specified for each experiment.

In some experiments, each blood-fed female was transferred to a tube ( 10 by $75 \mathrm{~mm}$ ) and restrained in the lower portion by a hollow glass insert with a cotton plug in the bottom. Water was added to the cotton plug for consumption and to maintain humidity in the confined space in the bottom of the tube. Mosquitoes were transferred to clean tubes at intervals, and the excreta were stored for analysis. When mosquitoes were dissected for F:G measurements at the end of the bloodmeal digestion period, any gut contents present were added to the excreta to be tested for hematin. In one experiment, females that had access to chicks overnight but did not feed were segregated into three groups at the same time the blood-fed females were placed in tubes. These groups were kept in 500-ml (0.0005 $\mathrm{m}^{3}$ ) plastic cages and given water, $1 \%$ sucrose, or $10 \%$ sucrose and incubated alongside the blood-fed females for $6 \mathrm{~d}$ at $18^{\circ} \mathrm{C}, 9: 15$ (L:D). The $18^{\circ} \mathrm{C}$ temperature was chosen because it has been reported that any blood meals taken by diapausing $C x$. pipiens result in fat body development and not ovarian development when the female is incubated at $18^{\circ} \mathrm{C}$ or below during the time the blood meal is being digested (Eldridge \& Bailey 1979).

The frequency of vitellogenesis initiation among diapausing females given $1 \%$ sucrose for 7 to $11 \mathrm{~d}$ before blood feeding was determined at incubation temperatures of 18,22 , and a daily $18-25^{\circ} \mathrm{C}$ cycle with the low and high temperatures corresponding to the times the lights turned on (0800 hours) and off (1700 hours). The photoperiod (9:15) was constant before and after feeding. In some experiments, nondiapausing colony females were fed at the same time and incubated alongside the diapausing females during the period of bloodmeal digestion.

A group of diapausing females was given an opportunity to store energy reserves by feeding on $10 \%$ sucrose ad lib. at $22^{\circ} \mathrm{C}, 9: 15$ (L:D) for 7 to 11 $\mathrm{d}$ and then $1 \mathrm{~d}$ at $18^{\circ} \mathrm{C}, 9: 15$ (L:D). Two hundred and thirty-six females from this group were transferred to $7( \pm 1)^{\circ} \mathrm{C}, 9: 15(\mathrm{~L}: \mathrm{D})$, and given only water thereafter. Samples were removed at intervals and tested for total lipids and total carbohydrates to monitor the depletion of energy reserves under simulated winter conditions. Initially, humidity was maintained by keeping a pan of water in the incubator and water vials with cotton wicks in the cage. On day 35 , a wet sponge was placed in the cage and kept moistened to increase the humidity and provide an additional source of drinking water.

To determine whether a diapausing female can obtain sufficient energy from a single blood meal to survive hibernation, the longevity of blood-fed, $1 \%$ sucrose-fed females, and nonblood-fed, $10 \%$ sucrose-fed females was compared under simulated winter conditions. A group of diapausing females was fed $1 \%$ sucrose ad lib. at $22^{\circ} \mathrm{C}, 9: 15$ (L:D) for 7 to $10 \mathrm{~d}$ and then offered a blood meal overnight. Sixty-eight blood-fed females were transferred to a clean cage with a wet sponge and water vials and placed at $7( \pm 1)^{\circ} \mathrm{C}, 9: 15$ (L:D). On the same day, 72 nonblood-fed females that had been given $10 \%$ sucrose for 7 to $8 \mathrm{~d}$ were placed in an adjacent cage that also was provided with a wet sponge and water vials. Thereafter, both groups were given only water, and mortality was monitored. We dissected ovaries from dead females in the blood-fed cohort to determine whether vitellogenesis had been initiated.

Assays. Blood samples were drawn from each chick by jugular venipuncture at the end of each feeding period and duplicate samples of 3,6 , and $9 \mu \mathrm{l}$ were mixed with $1 \mathrm{ml}$ of Drabkin's reagent for determination of hemoglobin titers using human hemoglobin (Sigma 525-18) as a standard 
Table 1. Reserves in diapausing and nondiapausing $C x$. pipiens females at eclosion and after being fed $10 \%$ sucrose for $7 \mathrm{~d}$

\begin{tabular}{|c|c|c|c|c|c|c|c|c|c|c|c|}
\hline \multirow{2}{*}{ Age and status } & \multicolumn{2}{|c|}{$\begin{array}{l}\text { Rearing and } \\
\text { maintenance } \\
\text { conditions }\end{array}$} & \multicolumn{3}{|c|}{ Cal. protein/8 } & \multicolumn{3}{|c|}{ Cal. lipids/q } & \multicolumn{3}{|c|}{ Cal. carbohyd./\% } \\
\hline & $\begin{array}{l}\text { Temp., } \\
{ }^{\circ} \mathrm{C}\end{array}$ & L:D & $n$ & $\bar{x}$ & SEM & $n$ & $\bar{x}$ & SEM & $n$ & $\bar{x}$ & SEM \\
\hline \multicolumn{12}{|l|}{$0-2 \mathrm{~h}$} \\
\hline $\begin{array}{l}\text { Nondiapausing } \\
\text { Nondiapausing } \\
\text { Diapausing }\end{array}$ & $\begin{array}{l}27 \\
22 \\
22\end{array}$ & $\begin{array}{r}14: 10 \\
14: 10 \\
9: 15\end{array}$ & $\begin{array}{l}10 \\
20 \\
10\end{array}$ & $\begin{array}{l}1.73 \\
2.59 \\
1.93\end{array}$ & $\begin{array}{l}0.07 \\
0.04 \\
0.05\end{array}$ & $\begin{array}{l}10 \\
20 \\
10\end{array}$ & $\begin{array}{l}1.08 \\
2.55 \\
2.54\end{array}$ & $\begin{array}{l}0.08 \\
0.04 \\
0.13\end{array}$ & $\begin{array}{l}10 \\
16 \\
10\end{array}$ & $\begin{array}{l}0.17 \\
0.24 \\
0.27\end{array}$ & $\begin{array}{l}0.02 \\
0.01 \\
0.01\end{array}$ \\
\hline \multicolumn{12}{|l|}{$7 \mathrm{~d}$} \\
\hline $\begin{array}{l}\text { Nondiapausing } \\
\text { Nondiapausing } \\
\text { Diapausing }\end{array}$ & $\begin{array}{l}27 \\
22 \\
22\end{array}$ & $\begin{array}{r}14: 10 \\
14: 10 \\
9: 15\end{array}$ & $\begin{array}{r}10 \\
12 \\
7\end{array}$ & $\begin{array}{l}1.77 \\
2.30 \\
2.43\end{array}$ & $\begin{array}{l}0.04 \\
0.06 \\
0.04\end{array}$ & $\begin{array}{r}12 \\
12 \\
7\end{array}$ & $\begin{array}{r}7.06 \\
6.64 \\
11.40\end{array}$ & $\begin{array}{l}0.29 \\
0.25 \\
1.12\end{array}$ & $\begin{array}{r}11 \\
11 \\
7\end{array}$ & $\begin{array}{l}1.23 \\
0.84 \\
1.93\end{array}$ & $\begin{array}{l}0.19 \\
0.12 \\
0.57\end{array}$ \\
\hline
\end{tabular}

(Briegel et al. 1979). The excreta in the tubes were dissolved in $1 \mathrm{ml}$ each of $1 \%$ lithium carbonate and used for hematin determinations (Briegel 1980). The stoichiometric molar relationship between bloodmeal hemoglobin and fecal hematin (Briegel 1986) made it possible to estimate the volume of blood retained by each female retrospectively at the end of the overnight feeding period.

The total amount of lipids in individual mosquitoes was determined by the method of Van Handel (1985a) using soybean oil $(0.5 \%$ in chloroform) as a standard. Micrograms of lipids were converted to calories $(1 \mathrm{mg}=9.09 \mathrm{cal})$. Nonnutritional and structural lipids are included in the totals for lipid reserves; however, this should not bias the results or alter the conclusions because these lipids measure only 0.2 to $0.3 \mathrm{cal}$ in most mosquito species (Van Handel 1985a).

Total carbohydrate determinations were made using the procedure described by Van Handel (1985b). Individual mosquitoes were crushed in 5 $\mathrm{ml}$ of anthrone reagent, heated for $20 \mathrm{~min}$ at $90^{\circ} \mathrm{C}$, and cooled in an ice bath. Glucose was used as a standard, and micrograms of carbohydrates were converted to calories $(1 \mathrm{mg}=4.0 \mathrm{cal})$. Corrections were not made for nonnutritional carbohydrate content because such amounts are consistently below $0.02 \mathrm{cal} /$ mosquito (Van Handel 1985b).

Total nitrogen content was determined by subjecting individual mosquitoes to a Kjeldahl digestion, quantifying with a Nessler reagent (Merck 9028 Basel, Switz.), and using ammonium sulphate as the standard (Minari \& Zilversmit 1963). The

Table 2. Lipid reserves in diapausing $C x$. pipiens at various times and feeding regimens before blood feeding, 9:15 (L:D), $22^{\circ} \mathrm{C}$

\begin{tabular}{lcrrrr}
\hline \hline $\begin{array}{c}\text { Posteclosion } \\
\text { diet }\end{array}$ & $\begin{array}{c}\text { Age of } \\
\text { 9 }\end{array}$ & $n$ & & \multicolumn{3}{c}{ Calories of lipid/\& } \\
\cline { 4 - 6 } & & & $\bar{x}$ & SEM & Range \\
\hline Not fed & $0-7 \mathrm{~h}$ & 8 & 2.10 & 0.12 & $1.48-2.58$ \\
$10 \%$ sucrose & $8-9 \mathrm{~d}$ & 9 & 8.68 & 0.38 & $6.95-10.28$ \\
$1 \%$ sucrose & $6-9 \mathrm{~d}$ & 18 & 3.38 & 0.20 & $1.91-5.02$ \\
\hline
\end{tabular}

nitrogen values were converted to protein by multiplying by 6.25 and expressed as calories $(1 \mathrm{mg}=$ $4.0 \mathrm{cal}$ ).

Data were compared for statistically significant differences by using Student's $t$ test (Snedecor \& Cochran 1967). In the text, arithmetic means are followed by standard errors of the means in parentheses.

\section{Results}

The protein, lipid, and carbohydrate content of nondiapausing and diapausing Cx. pipiens was determined under different temperature and photoperiod conditions in teneral adults and after feeding them $10 \%$ sucrose ad lib. for $7 \mathrm{~d}$ (Table 1 ). Teneral nondiapausing adult females reared at $22^{\circ} \mathrm{C}$ contained significantly more $(P<0.001)$ protein, lipid, and carbohydrate reserves than counterparts reared at $27^{\circ} \mathrm{C}$. Nondiapausing teneral females reared at $22^{\circ} \mathrm{C}$ also had significantly more $(P<$ $0.001)$ protein than diapausing females reared at the same temperature but at a shorter photophase. Nondiapausing and diapausing females reared at $22^{\circ} \mathrm{C}$ contained comparable amounts $(P>0.05)$ of lipids and comparable amounts of carbohydrates $(P>0.05)$ at eclosion.

After $7 \mathrm{~d}$ on a $10 \%$ sucrose diet, groups maintained at $22^{\circ} \mathrm{C}$ contained significantly more $(P<$ 0.001 ) protein than those kept at $27^{\circ} \mathrm{C}$. However, nondiapausing females maintained at $22^{\circ} \mathrm{C}$ no longer differed significantly $(P>0.05)$ in the amount of lipid reserves from counterparts kept at $27^{\circ} \mathrm{C}$. In contrast, diapausing females kept at $22^{\circ} \mathrm{C}$ and short-day conditions contained significantly more $(P \leq 0.01)$ lipid reserves than counterparts maintained at 22 and $27^{\circ} \mathrm{C}$ and long-day conditions. The data for carbohydrate reserves on day 7 are difficult to interpret because some mosquitoes may have contained sucrose in their crops when they were tested.

Data summarized in Table 2 show lipid reserves among diapausing sisters of females used for blood feeding. Teneral females contained significantly 
Table 3. Lipid reserves among diapausing $C x$. pipiens given $1 \%$ sucrose for 6 to $9 \mathrm{~d}$ before being given an opportunity to blood feed and then incubated for $6 \mathrm{~d}$ at $18^{\circ} \mathrm{C}, 9: 15$ (L:D)

\begin{tabular}{|c|c|c|c|c|c|}
\hline \multirow{2}{*}{ Status } & \multirow{2}{*}{ Subsequent diet } & \multirow{2}{*}{$n$} & \multicolumn{3}{|c|}{ Cal. lipids after $6 \mathrm{~d}$ incubation } \\
\hline & & & $\overline{\bar{x}}$ & SEM & Range \\
\hline Blood fed & Water & 56 & 2.83 & 0.14 & $1.03-6.05$ \\
\hline Did not blood feed & Water & 36 & 2.40 & 0.19 & $0.43-5.31$ \\
\hline Did not blood feed & $10 \%$ sucrose & 36 & 6.21 & 0.26 & $3.42-8.92$ \\
\hline Did not blood feed & $1 \%$ sucrose & 36 & 3.35 & 0.23 & $1.08-7.03$ \\
\hline
\end{tabular}

less $(P<0.05)$ lipids than the diapausing, teneral females used in the previous experiment (Table 1). However, after being fed $10 \%$ sucrose for 8 to $9 \mathrm{~d}$ (Table 2), they no longer differed significantly $(P$ $>0.05)$ from females treated similarly and tested on day 7 previously (Table 1). The lipid content of diapausing females that had been fed $1 \%$ sucrose for 6 to $9 \mathrm{~d}$ was significantly less $(P<0.001)$ than that of females given $10 \%$ sucrose for 8 to $9 \mathrm{~d}$. It was necessary to expand the age category for the $1 \%$ sucrose-fed cohort and use 6-7-d-old females as well as 8-9-d-old females in order to have sufficient numbers for the blood-feeding trial.

Diapausing females 6-9-d-old that had been fed $1 \%$ sucrose from the time of eclosion were offered a blood meal. At the end of the overnight exposure period, 65 of 201 (32.3\%) of the females contained blood. Blood-fed and nonblood-fed females were segregated and given water or sucrose as shown in Table 3. At the end of the 6-d period allowed for bloodmeal digestion, the lipid content of 56 surviving blood-fed females had decreased significantly $(P<0.05)$ from that of their sisters tested on the day the blood-feeding trial began and was not significantly $(P>0.05)$ different from that of their nonblood-fed sisters that had been given water and incubated for the same period. In contrast, the nonblood-fed sisters that were given 1 or $10 \%$ sucrose contained significantly more $(P<0.05$ and $P<0.001$, respectively) lipids at the end of the $6-d$ period than did the blood-fed females.

We plotted the amount of lipids in each of the 56 blood-fed females at the end of the 6-d period when blood was no longer visible in the gut against initial bloodmeal volumes to determine whether a correlation exists (Fig. 1). The correlation coefficient is -0.06 , and the slope of the regression line is -0.03 . Therefore, there is no significant $(P>$ 0.05 ) correlation between the volume of blood ingested and the amount of lipids present at the end of the digestion period. The average bloodmeal volume was $3.4( \pm 0.3) \mu$ l for the 56 females. An additional four females contained visible dark material, assumed to be undigested blood or hematin, on day 6 after feeding. These females were not tested for lipids. Instead, their guts and ovaries were dissected, and the gut contents were added to the excreta to be tested for hematin. Three of the females contained mature ovarian follicles, and the fourth had a few follicles with approximately $100 \mu \mathrm{m}$ of yolk. The average bloodmeal volume taken by these four females $(\bar{x}, 5.7 \pm 0.9 \mu \mathrm{l})$ was significantly greater $(P<0.001)$ than that taken by the 56 females with empty guts $(\vec{x}, 3.4 \pm 0.3$ $\mu \mathrm{l})$. It was not practical to dissect the ovaries of the 56 blood-fed females that were used for total lipid determinations because some lipids may have been lost in the process. However, the following results provide presumptive evidence that they were unlikely to have initiated vitellogenesis.

The initiation of vitellogenesis among $70 \mathrm{dia}-$ pausing $C x$. pipiens that had been given $1 \%$ sucrose for 7 to $11 \mathrm{~d}$ before blood feeding and incubated at various temperatures after blood feeding is shown in Table 4. Data on bloodmeal volumes also are summarized. Nondiapausing females used as controls had been fed $10 \%$ sucrose for 4 to $7 \mathrm{~d}$. Only 1 of $29(3 \%)$ diapausing females initiated vitellogenesis at $18^{\circ} \mathrm{C} ; 1$ of $17(6 \%)$ did so at $22^{\circ} \mathrm{C}$, and 4 of $24(17 \%) \mathrm{did}$ so at the $18-25^{\circ} \mathrm{C}$ cycle. With one exception, the diapausing females that initiated vitellogenesis (6 of 70 , or $8.6 \%$ ) took significantly larger $(P<0.05)$ blood meals than diapausing females that did not initiate vitellogenesis (Table 4). Each of the 29 nondiapausing, colony females took a large blood meal, and each developed mature ovarian follicles regardless of the incubation temperature.

Fifteen females in which diapause was terminated by exposure to long-day, high-temperature conditions still had hypertrophied fat bodies as indicated by an average lipid content of $8.3( \pm 0.3)$ $\mathrm{cal}$ at the end of the l-wk period. This valve does not differ significantly $(P>0.05)$ from diapausing females that had been maintained at short-day, cool-temperature conditions and fed $10 \%$ sucrose for 8 to $9 \mathrm{~d}$ before testing (Table 2). Some fat females in which diapause had been terminated were fed overnight on a chick, and all became gravid. The average blood volume retained by a sample of 31 of these females was $7.0( \pm 0.5) \mu 1$. This is significantly greater $(P<0.001)$ than the volumes retained by 64 diapausing females $(3.0 \pm$ $0.5 \mu \mathrm{l})$ with limited lipid reserves that failed to initiate vitellogenesis following blood feeding ( $\mathrm{Ta}$ ble 4). In comparison, average blood volumes retained by 439 fat, diapausing females and by 204 lean, nondiapausing females were $3.0( \pm 0.1) \mu \mathrm{l}$ and $8.9( \pm 0.2) \mu \mathrm{l}$, respectively. Therefore, the volume of blood retained depended upon whether the females were diapausing when fed and not on the size of the fat body. 


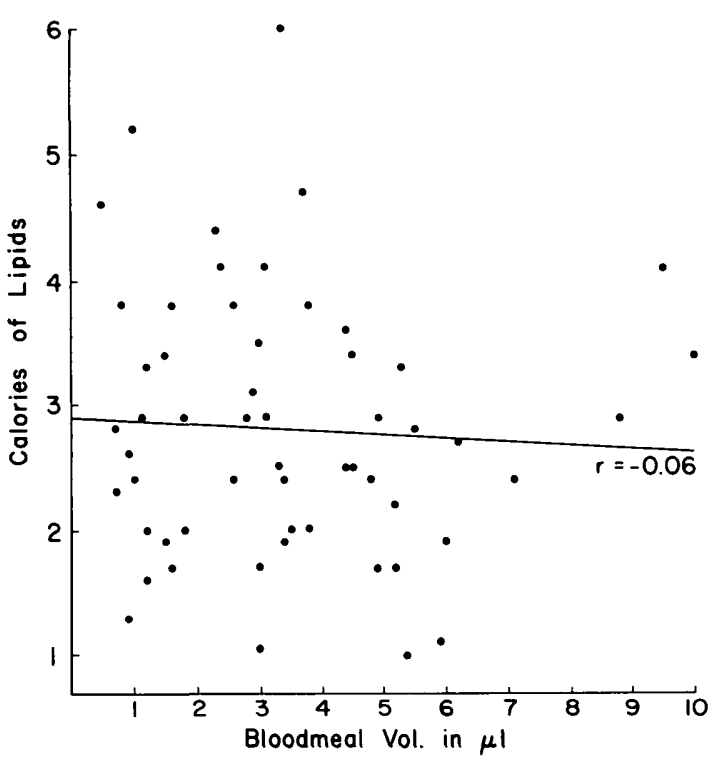

Fig. 1. Lack of correlation between bloodmeal volume and lipid content of diapausing $C x$. pipiens following digestion of the blood. The correlation coefficient $(r)$ is -0.06

Fig. 2 shows the depletion of lipid reserves in diapausing $C x$. pipiens that had been allowed to fill their fat depots by feeding on $10 \%$ sucrose before being transferred to simulated winter conditions and maintained on a water diet. Lipid reserves were slightly lower in the sample tested at the beginning of the experiment than in samples tested on days 14 and 28. Thereafter, significant $(P<0.05)$ decreases in the amount of total lipids occurred between days 28 and 42,70 and 84 , and 98 and 140. On the final day of the experiment (day 152), lipid reserves had been reduced to levels comparable to those observed previously in teneral diapausing females. Average carbohydrate content of females ranged from $0.05( \pm 0.01)$ cal to 0.39 $( \pm 0.08) \mathrm{cal}$. Significant increases $(P \leq 0.05)$ in the amount of carbohydrate reserves occurred between days 28 and 42 , and 70 and 84, and a significant drop occurred between days 98 and 140 .

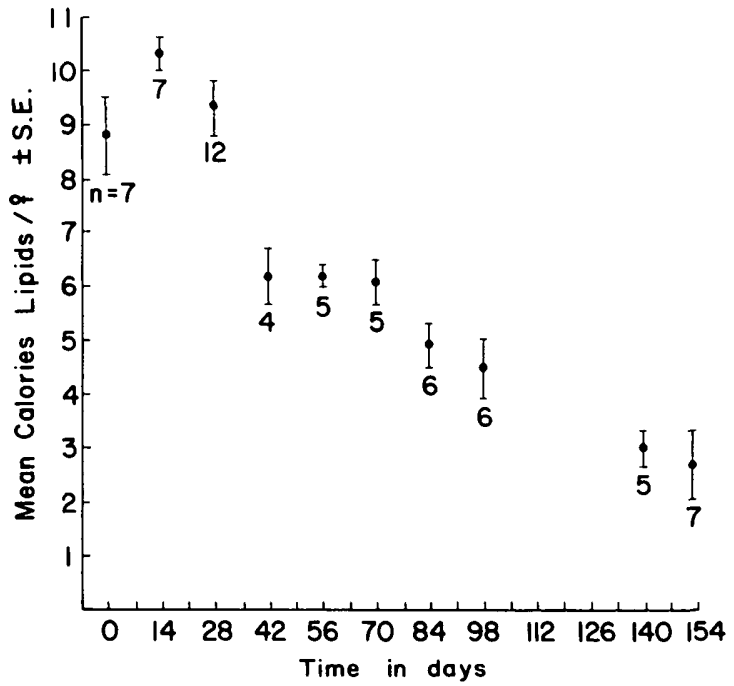

Fig. 2. Depletion of lipid reserves among fat, diapausing $C x$. pipiens maintained on a water diet after transfer to simulated winter conditions.

Mortality rates were high $(38 \%)$ during the first $35 \mathrm{~d}$ among the 236 females used in the foregoing experiment. After a wet sponge was placed in the cage on day 35 , attrition from mortality was only $20 \%$ during the remaining 117 days of the experiment. The remainder was from removal of live females for testing or dissection. Twenty-four females were still alive on the final day of the experiment (day 152 on a water diet at simulated winter conditions) when they were removed and tested or dissected. These females were 160 to 164 $\mathrm{d}$ old; they had been 8 to $12 \mathrm{~d}$ of age when they were placed in the incubator. Five females each were dissected for determination of $F: G$ ratios on the day the females were placed at simulated winter conditions (day 0 ) and on days $9,112,140$, and 152 thereafter. The number of females with diapausing ovaries on each of these days was $5,5,4$, 3 , and 1 , respectively.

The results of the longevity experiment comparing blood-fed females that had been given $1 \%$ sucrose for 7 to $10 \mathrm{~d}$ before blood feeding and

Table 4. Initiation of vitellogenesis and bloodmeal volumes in diapausing $C x$. pipiens with limited lipid reserves and nondiapausing controls incubated at various temperatures following blood feeding

\begin{tabular}{|c|c|c|c|c|c|c|c|c|}
\hline \multirow{3}{*}{ Status when fed } & \multirow{3}{*}{$\begin{array}{l}\text { Incubation } \\
\text { temp, }{ }^{\circ} \mathrm{C}\end{array}$} & \multirow{3}{*}{ No. fed } & \multicolumn{3}{|c|}{ Did not initiate vitellogenesis ${ }^{a}$} & \multicolumn{3}{|c|}{ Initiated vitellogenesis $b$} \\
\hline & & & \multirow{2}{*}{$n$} & \multicolumn{2}{|c|}{ Bloodmeal vol, $\mu \mathrm{l}$} & \multirow{2}{*}{$n$} & \multicolumn{2}{|c|}{ Bloodmeal vol, $\mu \mathrm{l}$} \\
\hline & & & & $\bar{x}$ & SEM & & $\bar{x}$ & SEM \\
\hline Diapausing & 18 & 29 & 28 & 2.9 & 0.4 & 1 & 2.3 & - \\
\hline Nondiapausing & 18 & 12 & 0 & - & - & 12 & 9.6 & 0.6 \\
\hline Diapausing & 22 & 17 & 16 & 2.8 & 0.6 & 1 & 7.3 & - \\
\hline Diapausing & $18-25$ & 24 & 20 & 3.3 & 0.6 & 4 & 11.4 & 1.7 \\
\hline Nondiapausing & $18-25$ & 17 & 0 & - & - & 17 & 10.0 & 0.4 \\
\hline
\end{tabular}

${ }^{a} \mathrm{~F}: \mathrm{G}$ ratio $<1.5: 1$; no visible yolk at $100 \times$ magnification.

${ }^{b} \mathrm{~F}: \mathrm{G}$ ratio $\geq 1.5: 1$; and, in this series of experiments, yolk lengths $\geq 60 \mu \mathrm{m}$. 


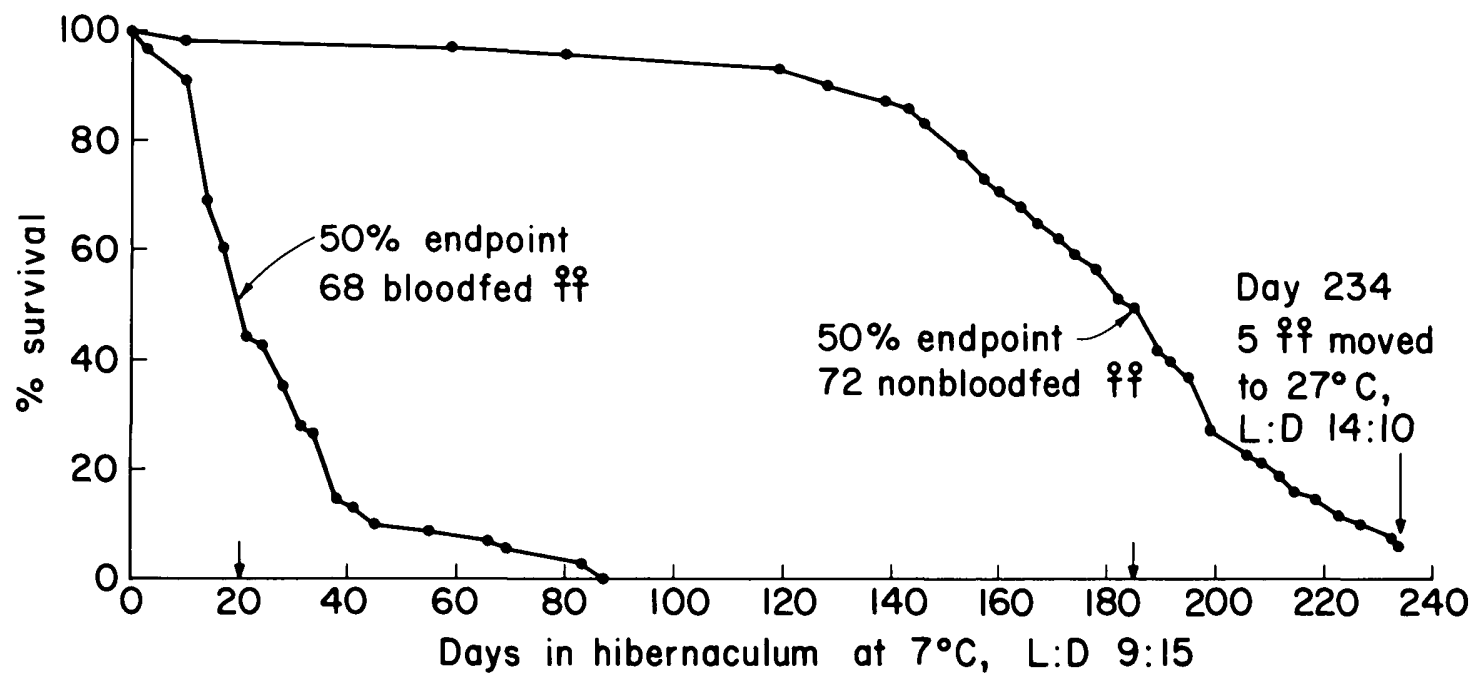

Fig. 3. Survival of diapausing Cx. pipiens that had been fed $1 \%$ sucrose and a single blood meal compared with nonblood-fed females fed only $10 \%$ sucrose before being transferred to simulated winter conditions and placed on a water diet.

nonblood-fed females that had been given $10 \%$ sucrose for the same period and then maintained on a water diet under simulated winter conditions are shown in Fig. 3. This experiment was designed to determine whether a single blood meal could provide sufficient energy reserves to allow females with limited lipid reserves to survive hibernation. The 50 and $95 \%$ mortality endpoints for the bloodfed mosquitoes was $20 \mathrm{~d}$ and $72 \mathrm{~d}$, respectively, and all mosquitoes were dead by day 87 . In contrast, $50 \%$ of the nonblood-fed mosquitoes were still alive on day 185 . Five mosquitoes $(7 \%)$ were still alive on day 234 at which time they were transferred to $27^{\circ} \mathrm{C}, 14: 10$ (L:D), and given $10 \%$ sucrose. Two days later they were fed on a chick. Four females oviposited and each egg raft hatched. The five females were kept at $27^{\circ} \mathrm{C}, 14: 10$ (L:D), and given $10 \%$ sucrose ad lib. One female each died on day $251,254,258,259$, and 260 , counting from the time of being placed in hibernation.

\section{Discussion}

The body composition of Cx. pipiens that we observed is in agreement with that reported by Twohy \& Rozeboom (1957) and Sakurai \& Makiya (1981) for anautogenous strains. In addition, females generally contained substantially more protein, lipid, and carbohydrate reserves at eclosion when reared at $22^{\circ} \mathrm{C}$ than at $27^{\circ} \mathrm{C}$, irrespective of whether they had been exposed to a diapause-inducing photoperiod (Table 1). However, nondiapausing teneral females reared at $22^{\circ} \mathrm{C}$ contained significantly more protein than diapausing females reared at the same temperature but at a shorter photophase. Adult body size and protein reserves, with the exception of vitellogenins synthesized from blood protein, are more or less fixed by the time of adult eclosion; therefore, the foregoing difference may have been due to sampling bias because sisters of these females no longer differed in protein content by day 7 after eclosion. The most interesting difference in regard to the physiology of diapause is in the lipogenic potential of diapausing and nondiapausing females. Despite having almost identical amounts of lipids at eclosion when reared at $22^{\circ} \mathrm{C}$, the diapausing females contained almost twice as much fat as their nondiapausing counterparts after $7 \mathrm{~d}$ on a $10 \%$ sucrose diet.

Makiya \& Sakurai (1975) showed a positive correlation between wing length and survivorship among overwintering Cx. pipiens, and wing length is also positively correlated with lipid reserves (Sakurai \& Makiya 1981; H.B., unpublished data). Tekle (1960) demonstrated an inverse relationship between body size in Cx. pipiens, as indicated by wing length, and the rearing temperature, and our results show that females reared at $22^{\circ} \mathrm{C}$ contain significantly more lipids at eclosion than individuals reared at $27^{\circ} \mathrm{C}$. Therefore, it follows that survivorship, and possibly other attributes, of diapausing $C x$. pipiens may be affected by the temperature at which the aquatic stages are reared.

Ovarian diapause can be induced in several $\mathrm{Cu}$ lex species, including $C x$. pipiens, by exposing the pupal stage to short photophases. Consequently, many laboratory experiments on diapause in Culex have been done with mosquitoes reared under standard long-day, high-temperature conditions before being transferred to diapause-inducing conditions as mature fourth instars or pupae (Eldridge 1968, 1987; Spielman \& Wong 1973; Eldridge et al. 1976; Eldridge \& Bailey 1979; Skultab \& Eldridge 1985). However, all larval instars as well as the pupal stage of Cx. pipiens respond to daylength (Oda \& Wada 1972, Sanburg \& Larsen 1973). Those observations 
on the effect of photoperiod, coupled with our results on the effect of rearing temperature, provide a strong argument for rearing $C x$. pipiens for diapause experiments under conditions that approximate as closely as practical those to which they would be exposed in nature.

Diapausing females with limited lipid reserves were obtained for the blood-feeding experiments by restricting their carbohydrate intake to $1 \%$ sucrose (Table 2). Such females increased their lipid reserves within 6 to $9 \mathrm{~d}$ from the time of eclosion by about $1.3 \mathrm{cal}$. In contrast, their sisters that were fed $10 \%$ sucrose for 8 to $9 \mathrm{~d}$ showed a fivefold greater increase of $6.6 \mathrm{cal}$. There is overwhelming evidence that the 56 females that were tested for lipid reserves $6 \mathrm{~d}$ after blood feeding failed to use the blood for increasing their lipid reserves (Table 3; Fig. 1). The lipid content of the blood-fed females actually decreased significantly, and in concert with that of nonblood-fed sisters maintained on an identical water diet, during the 6-d period. In addition, there was no correlation between lipid content of individual females and the volume of blood digested or excreted. A strong positive correlation would be expected if the blood were used for increasing lipid reserves. We found no evidence to support the contention that any blood meals taken by diapausing $C x$. pipiens result in fat body development and not ovarian development when the female is incubated at $18^{\circ} \mathrm{C}$ or below during the digestion period (Eldridge \& Bailey 1979).

Nonblood-fed females given 1 or $10 \%$ sucrose had significantly more lipid reserves than the bloodfed females at the end of the 6-d period. The females fed $1 \%$ sucrose (Table 3 ) simply maintained the reserve levels attained previously (Table 2); however, females transferred from 1 to $10 \%$ sucrose showed an average net gain of $2.8 \mathrm{cal}$ during the 6 -day period. This indicates that the lipogenic potential of the females was unimpaired and only required a suitable dietary substrate for its expression. Because blood was not used as a substrate for lipid synthesis, and because it is assumed that few of the 56 blood-fed females initiated vitellogenesis (see below), a question arises about the fate of the blood meal. This question is addressed separately (Mitchell \& Briegel 1989).

Incubation temperature during the time of bloodmeal digestion was not correlated with the initiation of vitellogenesis by diapausing females within the range of temperatures tested (Table 4). However, because the five diapausing females that initiated vitellogenesis at $22^{\circ} \mathrm{C}$ and $18^{\circ}-25^{\circ} \mathrm{C}$ also had taken significantly larger blood meals than the single female that did so at $18^{\circ} \mathrm{C}$, it is not possible to sort out temperature effects from bloodmeal volume effects in our small sample. The fact that $88 \%$ of the diapausing females failed to initiate vitellogenesis at $22^{\circ} \mathrm{C}$ and $18^{\circ}-25^{\circ} \mathrm{C}$ indicates that this is not gonotrophic dissociation in the classical sense (Swellengrebel 1929) if an incubation temperature of $18^{\circ} \mathrm{C}$, or below, is critical (Eldridge \& Bailey
1979). Instead, the failure of these females to initiate vitellogenesis is more likely the result of subthreshold bloodmeal volumes or incomplete digestion of the blood (Mitchell \& Briegel 1989).

In the study by Eldridge (1968) in which gonotrophic dissociation in Cx. pipiens was reported, diapausing females that contained even a trace of visible blood at the end of the feeding trial were included. However, even gonoactive Cx. pipiens that take subthreshold blood meals either fail to initiate vitellogenesis or to develop mature eggs (Mitchell et al. 1979, Mitchell \& Briegel 1989). In subsequent studies on gonotrophic dissociation in Cx. pipiens, an attempt was made to retain only "fully blood-fed" females from the feeding trials (Eldridge \& Bailey 1979), but visual estimates of the degree of engorgement by diapausing Cx. pipiens with well-developed fat bodies are highly inaccurate (unpublished data). Therefore, it is essential that future studies on gonotrophic dissociation in $C x$. pipiens include determinations of the bloodmeal volume of each female to rule out the effects of subthreshold volumes.

We observed a decrease in total lipids of about $65 \%$ over a 5 -mo period among diapausing $C x$. pipiens that had well-developed fat bodies at the time they were transferred to simulated winter conditions (Fig. 2). This is within the range reported for natural populations. Buxton (1935) indicated that $85 \%$ of the fat reserves of hibernating $C x$. pipiens is exhausted during hibernation; he found that the percentage of fat dropped from $61 \%$ of dry weight in October to $18 \%$ in March. Similarly, Eldridge (1987) noted a drop in the percentage of fat from $60 \%$ of dry body weight in September to $28 \%$ in mid-April. Therefore, our results on lipid storage levels and depletion rates confirm that the regimen used to rear diapausing females for experimental purposes was fully satisfactory. Further, $50 \%$ of such populations could be expected to survive a 6 -mo hibernation period without food after being allowed to fill their fat depots by feeding on $10 \%$ sucrose before entering hibernation (Fig. 3). The demonstration that 4 of 5 females that survived 234 days in hibernation took a blood meal and laid viable eggs indicates that extended hibernation $(7.8 \mathrm{mo})$ is possible by a small segment of nonblood-fed Cx. pipiens. Parenthetically, these results also indicate that Cx. pipiens colonies can be maintained over long periods with minimal effort by inducing diapause, feeding them $10 \%$ sucrose, and storing them at $7^{\circ} \mathrm{C}, 9: 15$ (L:D), and high humidity. Our observations on carbohydrate reserves were not revealing, and a more thorough study of triglyceride conversion and glycogen use by diapausing $C x$. pipiens is warranted.

The results of our longevity experiment (Fig. 3), also indicate that diapausing $C x$. pipiens with limited reserves cannot obtain sufficient energy from a single blood meal to survive extended hibernation. In a related study, Bailey et al. (1982) reported reduced survival rates among blood-fed, diapaus- 
ing females that became gravid. However, this cannot explain the high mortality observed among the blood-fed females in our study because none of the females became gravid.

Bailey et al. (1982) concluded that diapausing $C x$. pipiens that take a prehibernation blood meal and do not develop eggs can survive the winter at rates comparable to diapausing nonblood-fed mosquitoes. However, they fed their mosquitoes carbohydrates in the form of apple slices before and after blood feeding. Our results show that sugar alone, when fed for 7 to $8 \mathrm{~d}$ before hibernation in the form of $10 \%$ sucrose, is sufficient to assure winter survival of a significant segment of the diapausing population. Therefore, in the study of Bailey et al. (1982), it is impossible to distinguish between the effect of the single blood meal and the effects of the carbohydrate meals. Their results show that a single blood meal taken by presumably fat diapausing $C x$. pipiens does not adversely affect winter survival if the blood meal does not result in oögenesis. Their results do not show any salubrious effect of the blood meal or that such a blood meal enhances the chances of winter survival. The question then arises, should a diapausing female with lipid reserves adequate for winter survival take the risks attendant with blood feeding if the blood meal does not offer some beneficial effect? The absence of host-seeking behavior in diapausing $C x$. pipiens (Mitchell 1983, Bowen et al. 1988) may preclude the taking of such risks by females destined to survive the winter in nature.

Guelmino (1951), working with two anophelines from Yugoslavia, speculated that formation of fat body by diapausing females is a primary process that has an "antigonadotrophic" influence. Our results with diapausing $C x$. pipiens do not support this idea. Whether Cx. pipiens is diapausing is more important than the size of the fat body in regulating blood retention and initiation of vitellogenesis. Most diapausing females retained small quantities of blood regardless of fat body size, and most failed to initiate vitellogenesis; whereas fat females that had terminated diapause and lean nondiapausing females retained significantly larger blood volumes, and all became gravid. As indicated above, the failure of the diapausing females to initiate vitellogenesis probably was due to subthreshold bloodmeal volumes or incomplete digestion of the blood.

\section{Summary and Conclusions}

Our results refute the contention that diapausing $C x$. pipiens can use a blood meal to synthesize lipids; therefore, a prehibernation blood meal would not enhance chances for overwinter survival.

Sugar is a suitable substrate from which diapausing $C x$. pipiens can synthesize and store sufficient lipid reserves, within a relatively short prehibernation period, to survive hibernation. Therefore, studies designed to measure the effect of a blood meal on lipid reserve levels or overwinter survival must distinguish the effect of carbohydrate meals, taken before or after blood feeding, from that of the blood.

The physiological state of the female with regard to diapause, and not the size of the fat body, is critical in regulating blood retention and initiation of vitellogenesis. Small blood meals did not initiate vitellogenesis, probably because of subthreshold volumes. Because most blood-fed, diapausing females did not initiate vitellogenesis even when incubated at permissive warm temperatures during the time of digestion, gonotrophic dissociation can be ruled out.

Termination of ovarian diapause occurred in concert with depletion of lipid reserves under constant cool-temperature and short-day conditions.

\section{Acknowledgment}

We thank S. Zaba for maintaining the stock mosquito colony and R. Haigis for assistance with the chemical analyses. We appreciate the contributions made by the Swiss National Science Foundation (Nr. 3.149.85 to H.B.) and the support given by the "Georges and Antoine Claraz-Schenkung, Zurich," as well as the "Stiftung für wissenschaftliche Forschung an der Universität Zürich." We are especially grateful to Ray E. Bailey, Centers for Disease Control, Fort Collins, Colo., for performing the statistical analysis, and to Mary F. Bowen, Northern Illinois University, DeKalb, for her critical reading of the manuscript.

\section{References Cited}

Bailey, C. L., M. E. Faran, T. P. Gargan \& D. E. Hayes. 1982. Winter survival of blood-fed and non bloodfed Culex pipiens L. Am. J. Trop. Med. Hyg. 31: 1054-1061.

Bowen, M. F., E. E. Davis \& D. A. Haggart. 1988. A behavioral and sensory analysis of host seeking behavior in the diapausing mosquito Culex pipiens. J. Insect Physiol. 34: 805-813.

Briegel, H. 1980. Determination of uric acid and hematin in a single sample of excreta from blood-fed insects. Experientia 36: 1428.

1986. Protein catabolism and nitrogen partitioning during oögenesis in the mosquito Aedes aegypti. J. Insect Physiol. 32: 455-462.

Briegel, H., A. O. Lea \& M. J. Klowden. 1979. Hemoglobinometry as a method for measuring bloodmeal sizes of mosquitoes (Diptera: Culicidae). J. Med. Entomol. 15: 235-238.

Buxton, P. A. 1935. Changes in the composition of adult Culex pipiens during hibernation. Parasitology 27: 263-265.

Eldridge, B. F. 1968. The effect of temperature and photoperiod on blood-feeding and ovarian development in mosquitoes of the Culex pipiens complex. Am. J. Trop. Med. Hyg. 17: 133-140.

1981. Vector maintenance of pathogens in adverse environments (with special reference to mosquito maintenance of arboviruses), pp. 143-157. In J. J. McKelvey, B. F. Eldridge \& K. Maramorosch [eds.], Vectors of disease agents. Praeger, New York.

1987. Diapause and related phenomena in Culex mos- 
quitoes: their relation to arbovirus disease ecology. Curr. Top. Vector Res. 4: 1-28.

Eldridge, B. F. \& C. L. Bailey. 1979. Experimental hibernation studies in Culex pipiens (Diptera: Culicidae): reactivation of ovarian development and blood feeding in prehibernating females. J. Med. Entomol. 15: $462-467$.

Eldridge, B. F., M. D. Johnson \& C. L. Bailey. 1976. Comparative studies of two North American mosquito species, Culex restuans and Culex salinarius: response to temperature and photoperiod in the laboratory. Mosq. News 36: 506-513.

Guelmino, D. J. 1951. The physiology of Anopheles maculipennis during hibernation. An attempt to interpret the phenomenon of gonotrophic dissociation. Ann. Trop. Med. Parasitol. 45: 161-168.

Lea, A. O. 1964. Studies on the dietary and endocrine regulation of autogenous reproduction in Aedes taeniorhynchus (Wied.). J. Med. Entomol. 1: 40-44.

Makiya, K. \& H. Sakurai. 1975. Survival of the overwintering house mosquito, Culex pipiens pallens, with special reference to the relation between wing length and survival rate. Jpn. J. Sanit. Zool. 26: 7-14.

Minari, O. \& D. B. Zilversmit. 1963. Use of $\mathrm{KCN}$ for stabilization of color in direct Nesslerization of Kjeldahl digests. Anal. Biochem. 6: 320-327.

Mitchell, C. J. 1983. Differentiation of host-seeking behavior from blood-feeding behavior in overwintering Culex pipiens (Diptera: Culicidae) and observations on gonotrophic dissociation. J. Med. Entomol. 20: $157-163$.

Mitchell, C. J. \& H. Briegel. 1989. Fate of the bloodmeal in force-fed, diapausing Culex pipiens. J. Med. Entomol. 26: 332-341.

Mitchell, C. J., G. S. Bowen, T. P. Monath, C. B. Cropp \& J. A. Kerschner. 1979. St. Louis encephalitis virus transmission following multiple feeding of $\mathrm{Cu}$ lex pipiens pipiens (Diptera: Culicidae) during a single gonotrophic cycle. J. Med. Entomol. 16: 254-258.

Oda, T. \& Y. Wada. 1972. Developmental stages of Culex pipiens pallens sensitive to photoperiodic conditions. Trop. Med. (Nagasaki): 198-202.

Sakurai, H. \& K. Makiya. 1981. Body composition of Culex pipiens pallens with special reference to body size of overwintering females. Jpn. J. Sanit. Zool. 32: $72-74$.

Sanburg, L. L. \& J. R. Larsen. 1973. The effect of photoperiod and temperature on ovarian development in Culex pipiens pipiens L. J. Insect Physiol. 19: 1173-1190.

Skultab, S. \& B. F. Eldridge. 1985. Ovarian diapause in Culex peus Speiser (Diptera: Culicidae). J. Med. Entomol. 22: 454-458.

Snedecor, G. W. \& W. G. Cochran. 1967. Statistical methods, 6th ed. Iowa State University Press, Ames.

Spielman, A. \& J. Wong. 1973. Studies on autogeny in natural populations of Culex pipiens. III. Midsummer preparation for hibernation in autogenous populations. J. Med. Entomol. 10: 319-324.

Swellengrebel, N. H. 1929. La dissociation des fonctions sexuelles et nutritives: (dissociation gono-trophique) d'Anopheles maculipennis comme cause du paludisme dans les Pays-Bas et ses rapports avec "l'infectión domiciliaire." Ann. Inst. Pasteur 43: 13701389 (in French).

Tekle, A. 1960. The physiology of hibernation and its role in the geographical distribution of populations of the Culex pipiens complex. Am. J. Trop. Med Hyg. 9: 32l-330.

Twohy, D. W. \& L. E. Rozeboom. 1957. A comparison of food reserves in autogenous and anautogenous Culex pipiens populations. Am. J. Hyg. 65: 316-324.

Van Handel, E. 1965. The obese mosquito. J. Physiol 181: 478-486.

1985a. Rapid determination of total lipids in mosquitoes. J. Am. Mosq. Control Assoc. 1: 302-304.

1985b. Rapid determination of glycogen and sugars in mosquitoes. J. Am. Mosq. Control Assoc. 1: 299301.

Wilton, D. P. \& G. C. Smith. 1985. Ovarian diapause in three geographic strains of Culex pipiens (Diptera: Culicidae). J. Med. Entomol. 22: 524-528.

Received for publication 27 June 1988; accepted 3 October 1988. 